Western University Scholarship@Western

1980

\title{
Self-Selection and Interprovincial Migration in Canada
}

Chris Robinson

Nigel Tomes

Follow this and additional works at: https://ir.lib.uwo.ca/economicsresrpt

Part of the Economics Commons

Citation of this paper:

Robinson, Chris, Nigel Tomes. "Self-Selection and Interprovincial Migration in Canada." Department of Economics Research Reports, 8019. London, ON: Department of Economics, University of Western Ontario (1980). 
RESEARCH REPORT 8019

SELF-SELECTION AND INTERPROVINCIAL

MIGRATION IN CANADA*

by

Chris Robinson

and

Nige1 Tomes

\author{
Department of Economics \\ University of Western Ontario \\ London \\ Canada
}

October 1980

* A preliminary version of this paper was presented at the Labour Workshop U.W.O.; workshop participants provided helpful comments . 


\section{ABSTRACT}

The estimated returns to migration based on comparisons of the wages of movers with those of similar stayers may be biased due to self-selection. Using 1971 Census micro data we find evidence of self-selection and estimate selectivity-corrected wages individuals could have earned as movers and stayers. A structural probit equation is estimated which is equivalent to the 'human capital' migration regression of previous aggregate studies. We find that individual migration depends on the potential wage gains; language influences migration consistent with an information hypothesis; and additional education increases the mobility of most groups, but reduces the mobility of Quebec francophones. 


\section{SELF-SELECTION AND INTERPROVINCIAL MIGRATION}

\section{IN CANADA}

\section{Chris Robinson and Nigel Tomes}

1. Introduction

There has been considerable debate concerning the extent to which migration has served as an adjustment mechanism alleviating economic imbalances between Canadian provinces. The crucial issue concerns the responsiveness of migration to differentials in incomes and unemployment rates between provinces. Economic theory predicts such an adjustment mechanism. Models which view an individual's migration as a human capital investment (Sjaastad 1962) predict that an individual will move from location $i$ to $j$ if the present value of additional earnings associated with the location change exceed the costs of the move. Although based on models of individual maximization, empirical research on interprovincial migration flows has, for the most part, relied upon aggregate data. The standard 'human capital' regression equation relates the (gross or net) migration flow between provinces (or regions, etc.) to the average incomes and unemployment rates in the origin and destination provinces, the distance between provinces and possibly other variables (age, education, language, etc.) (McInnis 1969; Courchene 1970, 1974; Vanderkamp 1971; Laber and Chase 1971; Grant and Vanderkamp 1976, Ch. 3). The empirical findings are in the predicted directions--a higher average income or lower unemployment rate in the destination province increases in-migration while the same changes in the origin province reduce out-migration, other things equal. Studies employing aggregate data have provided important insights into the role of migration as an economic adjustment mechanism and the influence of government policy variables on migration flows. However the question remains concerning whether individual migration behavior conforms to the 
findings of aggregate studies. It is not uncommon for micro-studies to reach conclusions which differ dramatically from the corresponding macro results. Furthermore, problems arise in interpreting the results of aggregate migration regressions as tests of an individual-based theory of migration behavior. In particular the coefficients of aggregate migration regressions do not in general represent estimates of the structural relationships implied by the human capital theory of migration. A structural interpretation is appropriate only if the population is homogeneous. In this case the average income and unemployment rate measure what an individual would experience in each province. However such a model cannot adequately explain the sizeable reverse migration flows from 'attractive' (higher income, lower unemployment) provinces to those which are (on average) less attractive. The existence of heterogeneity in the population offers an obvious explanation for this phenomenon. Thus an individual will move from Ontario to Newfoundland, contrary to the prevailing migration flow, if his expected lifetime income is increased, even though the average expected income in Newfoundland is lower. Once such heterogeneity is recognized the coefficients of aggregate regression equations can no longer be interpreted as the structural coefficients of the "typical individual", rather, they represent the outcome of both movements across the distribution of individual characteristics and individual responses. ${ }^{2}$ In this paper we conduct empirical tests of the 'human capital' migration model using individual data. Conceptually, this is a more appropriate test of a theory of individual migration behavior. The use of micro data allows us to take account of heterogeneity. We estimate a structural probit equation which is the micro equivalent of the equation estimated in the aggregate studies cited earlier. 
Two recent Canadian studies utilize individual data to examine the relationship between income and migration. Marr and Millerd (1978, forthcoming) using 1971 Census data find the incomes of 'lifetime' interprovincial migrants to be significantly higher than that of stayers. Grant and Vanderkamp (1980) in an important paper analyze the effects of recent migration (within the preceding five years) on the 1971 incomes of individuals in a large panel study. They find that, although the initial returns to migration are negative, most males and persons in the lower half of the income distribution receive positive payoffs after a few years. 3

These micro studies estimate the returns to migration, which are the other side of the coin to the aggregate studies--having income as the dependent variable and migration as a right-hand side variable. However it is widely recognized that estimates of the returns to migration are subject to selectivity bias. This problem arises because observed patterns of migration are not the outcome of a controlled experiment in which a randomly selected experimental group is migrated and the control group remains in the origin location. Rather, observed migration behavior is the outcome of maximizing behavior on the part of economic agents. Thus :

"[T]he fact that individual A migrates, while otherwise comparable $B$ does not, suggests that an important difference does exist between the individuals... . Individual A may be more motivated to invest in human capital formation, not only in migration, but in other forms as well. If such were the case, the earnings of the remaining cohort from which the migrant is drawn may provide a lower bound for the earnings the migrant would have received in the absence of migration." Greenwood (1975), p. 402.

If this is the case the estimated returns to migration will be upward biased. This assumes that there is only one kind of ability or "motivation" that is useful in all locations. However if this is not the case and individuals differ in their comparative advantage in performing tasks located in different regions, the process of self-selection may lead to either upward or downward biased estimates of the returns to migration. In this paper we employ recently developed 
techniques to correct for selectivity bias (Hecloman 1976, 1979; Willis and Rosen 1979) while estimating to returns to various characteristics for movers and stayers. Our estimates of the selectivity-corrected returns to various characteris- a tics for movers and stayers enable us to estimate the "opportunity wages" of individuals--that is, the wages of migrants-had-they-stayed and of stayers-ifthey-had-moved. More importantly, this paper goes a step further to estimate the responsiveness of individual migration to the expected returns. To our knowledge this is one of the few studies to apply this econometric methodology to analyze individual migration behavior, and the first such study using Canadian micro data. 4

The remainder of the paper proceeds as follows: Section 2 presents the model. Section 3 describes the relevant characteristics of the 1971 Canadian Census data--utilized in this study. Our empirical findings concerning the determinants of 'lifetime' interprovincial migration (between the completion of schooling and 1971) are presented in Section 4. A brief conclusion follows in Section 5 .

\section{A Model of Migration and Self-Selection}

The human capital approach to migration suggests that (abstracting from differences in consumption aspects) individuals will choose the sequence of locations over the lifetime which will maximize the present value of earnings net of moving costs. If earnings skills are perfectly transferable across locations (i.e., no lpcation specific skills) and age- or experience-earnings profiles associated with different locations exhibited multiple intersections, then provided the direct costs of moving are moderate, a large number of moves may be involved in the optimal sequence. In the extreme case of zero moving costs 
the observed earnings stream would be the 'outer envelope' of the earnings profiles of all locations, $i . e .$, for each individual the observed wage: $W_{t}^{*}=\max \left(W_{1 t}\right)$ for all $\therefore$, where $W_{i t}$ is the individual's potential wage in location $i$ in period $t$. In fact for most Canadians interprovincial, or interregional migration is an infrequent occurrence. One explanation for this is the existence of job and location specific skills. Indeed, location specific skills, induced in part by job specific skills, may be as important as the declining payoff period in explaining the observed tendency of migration rates to decrease with age. The model we develop in this section emphasizes the importance of such firm and hence location specific skills.

If location specific skills are of sufficient importance, individuals can be viewed as facing an all-or-nothing migration choice at the commencement of their working life. In this respect we are adopting a standard model in analyses of educational and occupational choices. However, contrary to simple choice models, we assume that each individual faces a pair of profiles unique to him, rather than the average profile pair for a person of his type, thus allowing for heterogeneity in the population. If moving costs were zero, each individual would be observed in the location with the highest present value of lifetime earnings. Note that this does not imply the condition, $w_{t}^{*}=\max \left(w_{i t}\right)$ for all $t$, derived for the case of perfectly mobile skills, although that condition must hold for some $t$. In the presence of location-specific skills the observed earnings (wage) profile is no longer necessarily the 'outer envelope' of all possible profiles. Indeed during some periods an individual may well be observed earning a lower wage rate in his existing location than he would have received in an alternative location.

Consider then the choice facing individual $i$ located in area $b$ and considering migrating to area a. Let $y_{a_{i}}$ and $y_{b_{i}}$ be "permanent" incomes or wealth for individual $i$ in $a$ and $b$ respectively; individual $i$ will then move from $b$ to $a$ provided:

$$
y_{a_{i}}-y_{b_{i}}-c_{i}>0
$$

or

$$
y_{a_{i}}-y_{b_{i}}\left(1+c_{i}\right)>0
$$


where $c_{i}$ is the present value or permanent income equivalent of the costs to individual $i$ of moving from $b$ to $a$, and $c_{i}=c_{i} / y_{b_{i}}$. Defining:

$$
I_{i} \equiv \ln \left(\frac{y_{a_{i}}}{y_{b_{i}}\left(1+c_{i}\right)}\right)=\ln y_{a_{i}}-\ln y_{b_{i}}-c_{i}
$$

the criterion for migrating becomes $I_{i}>0$. Thus the probability of an individual migrating from $b$ to a depends positively on the permanent income level he may expect in a and negatively on his migration costs and his permanent income level if he remains in b. Our primary purpose is to estimate the "structural" probit equation implied by (2). Since direct measures of what migrant 1 would have earned had he not migrated, etc, are not available, we proceed in a manner analogous to Willis and Rosen (1979) to obtain estimates of $\ln y_{a_{i}}$ and $\ln y_{b_{i}}$. First, we specify the earnings functions for the two areas as :

$$
\begin{aligned}
& \ln y_{a_{i}}=x_{i} \beta_{a}+u_{a_{i}} \\
& \ln y_{b_{i}}=x_{i} \beta_{b}+u_{b_{i}}
\end{aligned}
$$

where

$$
\begin{aligned}
& x_{i}=\begin{array}{c}
\text { \{Schooling, Experience, Degree, Training, Ability, } \\
\text { Language, Urban/Rural/Farm Location }\}_{i} \\
\text { (observable) }
\end{array} \\
& u_{a_{i}}=\begin{array}{c}
\left\{\text { General Ability not in } x_{i},\right. \text { Specific capital useful } \\
\text { in } a\}_{i}
\end{array} \\
& u_{b_{i}}=\begin{array}{c}
\text { (Genobservable) } \\
\text { in } b\}_{i}
\end{array}
\end{aligned}
$$

Over the entire population of individuals initially located in $b, u_{i}$ and $u_{b_{i}}$ have zero means, variances $\sigma_{a a}, \sigma_{b b}$ and covariance $\sigma_{a b}$. In general, the covariance, $\sigma_{a b}$, is unrestricted and in our estimation procedure no restrictions are imposed. If unobserved talents making an individual more productive in location $i$ also make him more productive in other locations--a hierarchical interpretation viewing 
unobserved talent as unidimensional--then $\sigma_{a b}>0$; a theory of comparative advantage with multidimensional unobserved talent would permit $\sigma_{a b}<0$. The specification of the earnings function in terms of schooling and experience follows the semi-log form proposed by Mincer (1974). This specification has received empirical support against alternative functional forms in the work of Heckman and Polachek (1974) and Welland (1978). We augment the earnings function with measures of training, urban/rural location and ability proxies available in our data set, in addition to language variables of importance in a Canadian context. Including measures of post-school training in the form of apprenticeship or vocational training programs allows the wage experience profiles of these individuals to differ from those individuals with only informal on-the-job-training. This is obviously an imperfect proxy for post-school investment, and indeed there is no definite presumption that "formal" training or investment and total investment are positively correlated, hence the estimated coefficients on these variables must be interpreted with care. Proxies for family background and ability are included to capture a variety of effects due to "ability", "motivation", etc. [Greeley, 1976], and to test the suggestion that the sons of immigrants may be more able than the sons of natives due to self-selection in international migration [Chiswick, 1977]. $B_{a}$ and $B_{b}$ are not constrained to be equal, allowing rates of return for each characteristic to vary by location. Different rates of return to schooling by province, for example, were reported by Chiswick (1976).

The costs of moving from $b$ to a are assumed proportional to permanent income in the origin area with the factor of proportionality given by:

$$
c_{i}=z_{i} \delta+u_{c_{i}}
$$

where $z_{i}=$ Family Size, Language, Family Background, Marital

$$
\text { Status, Schooling }]_{i}
$$

$$
u_{c_{i}}=\{\text { Unobservable Cost Components }\}_{i}
$$


Across the entire population of $b, u_{c_{1}}$ has zero mean, variance $\sigma_{c c}$ and covariances $\sigma_{a c}$ and $\sigma_{b c}$ which in general are unrestricted. This specification of the costs of moving includes the usual variables found to be important in the literature. It is usually argued that the presence of school age children, inhibits moving on the grounds that costs will be incurred changing schools, etc. Marital status affects the cost of moving since a member of a family unit has to take into account the change in earnings of other family members. Mincer (1978) shows that the presence of a spouse inhibits migration relative to unattached individuals. On the other hand, married men are likely to specialize more in the market which, for a given hourly wage rate difference, makes them more likely to migrate. Schooling is also hypothesized to affect the cost of moving on the grounds that it yields a return, in addition to wage effects, in the form of reduced costs of information both concerning job prospects and the cost of moving [Schwartz (1973)]. In bilingual Canadian society, language may also influence the cost of moving via "cultural ties" and information costs.

The earnings functions (3) and (4) cannot be estimated for all individuals originally resident in a given location $b$. Part of $b$ 's population moves and part stays: for the movers we observe $\ln y_{a_{i}}$ but not $\ln y_{b_{i}}$; for the stayers we observe $\ln y_{b_{i}}$ but not $\ln y_{a_{i}}$. Thus both (3) and (4) have to be estimated on truncated samples. Those individuals for whom $I_{i}>0$ move, hence the regression function for (3); estimated on movers only, is :

$$
E\left(\ln y_{a_{i}} \mid x_{i}, I_{i}>0\right)=x_{i} \beta_{a}+E\left[u_{a_{i}} \mid I_{i}>0\right]
$$

Conversely, (4) must be estimated on the sample of stayers for whom $I_{1}<0$, hence the regression function in this case is:

$$
E\left(\ln y_{b_{i}} \mid x_{i}, I_{i}<0\right)=x_{i} \beta_{b}+E\left[u_{b_{i}} \mid I_{i}<0\right]
$$

Substituting from (3)-(5) into (2) yields the reduced form selection index:

$$
\begin{aligned}
I_{i} & =x_{i}\left(\beta_{a}-\beta_{b}\right)-z_{i} \delta+\left(u_{a_{i}}-u_{b_{i}}-u_{c_{i}}\right) \\
& \equiv w_{i} \Pi-\varepsilon_{i}
\end{aligned}
$$


where $W=\left[x_{i}, z_{i}\right], I^{\prime}=\left[\left(\beta_{a}-\beta_{b}\right), \delta\right],-\epsilon_{i}=u_{a_{i}}-u_{b_{i}}-u_{c_{i}} \cdot$

Using this index and assuming normality for $u_{a_{i}}, u_{b_{i}}$ and $u_{c_{u}},(6)$ and (7) may be written:

$$
\begin{aligned}
& E\left(\ln y_{a_{i}} \mid x_{i}, I_{i}>0\right)=x_{i} \beta_{a}+\frac{\sigma_{a \epsilon}}{\sigma_{\epsilon}} \lambda_{a_{i}} \\
& E\left(\ln y_{b_{i}} \mid x_{i}, I_{i}<0\right)=x_{i} \beta_{b}+\frac{\sigma_{b \epsilon}}{\sigma_{\epsilon}} \lambda_{b_{i}}
\end{aligned}
$$

where

$$
\begin{aligned}
& \lambda_{a_{i}} \equiv E\left[\frac{\epsilon}{\sigma_{\epsilon}} \mid \frac{\epsilon_{i}}{\sigma_{\epsilon}}<\frac{W_{i} \Pi}{\sigma_{\epsilon}}\right]=-f\left(\frac{W_{i} \Pi}{\sigma_{\epsilon}}\right) / F\left(\frac{W_{i} \Pi}{\sigma_{\epsilon}}\right)<0 \\
& \lambda_{b_{i}} \equiv E\left[\frac{\epsilon}{\sigma_{\epsilon}} \mid \frac{\epsilon_{i}}{\sigma_{\epsilon}}>\frac{W_{i} \Pi}{\sigma_{\epsilon}}\right]=f\left(\frac{W_{i} \Pi}{\sigma_{\epsilon}}\right) /\left[1-F\left(\frac{W_{i} \Pi}{\sigma_{\epsilon}}\right)\right]>0
\end{aligned}
$$

where $f(\cdot)$ and $F(\cdot)$ are the normal density function and cumlative distribution function respectively.

Estimates of $\beta_{a}$ and $\beta_{b}$ may be obtained by first estimating a probit for the reduced form index (8). The probit coefficients may then be used to compute the $\lambda_{a_{i}}$ and $\lambda_{b_{i}}$ and these in turn may be used in the truncated regressions (9) and (10) to obtain consistent estimates of $\beta_{a}$ and $\beta_{b}$ (Heckman 1979). Finally, the consistent estimates of $\beta_{a}$ and $\beta_{b}$ may be used to form consistent predictors for $\ln y_{a_{i}}$ and $\ln y_{b_{i}}$, and these may be included in the structural index:

$$
I_{i}=\left(\hat{x_{i}} \beta_{a}\right)-\left(\hat{x}_{i} \beta_{b}\right)-z_{i} \delta-\epsilon_{i}
$$

The probability that an individual chooses to move is then given by:

$$
\operatorname{Pr}\left\{\left[\left(\mathrm{x}_{i} \hat{\beta}_{a}\right)-\left(\mathrm{x}_{i} \hat{\beta}_{b}\right)-\mathrm{z}_{i} \delta\right] / \sigma_{\epsilon}>\frac{\epsilon_{i}}{\sigma_{\epsilon}}\right\}
$$

The probit coefficient on the predicted earnings differential $\left\{\left(\hat{x_{i} \beta_{a}}\right)-\left(\hat{x_{i}} \beta_{b}\right)\right\}$ is thus $1 / \sigma_{\varepsilon}>0$. This restriction may be tested by estimating the probit (12). 
will make them move. For the investigator this fraction is the probability that an individual with characteristics $\mathrm{x}_{1}$ will move, because the investigator knows only the distribution of $\epsilon_{i}$. For each individual the decision to move or not to move has no probabilistic aspect since each individual knows his own realization of $\epsilon_{i}$ )

The data available to us only contain one observation on the ageearnings or experience earnings profile of each individual. The model above has been specified with this restriction in mind, having only a single variable (permanent income) to characterize an individual's profile in each location. This data restriction has several important implications for the estimation. Suppose, for example, that job and location specific skills are important and movers typically move (at time $t_{0}$ ) from flatter to steeper proviles yielding them a higher 1ifetime (permanent) wage; e.g., from I to II in Figure 1 below.

\section{Figure 1}

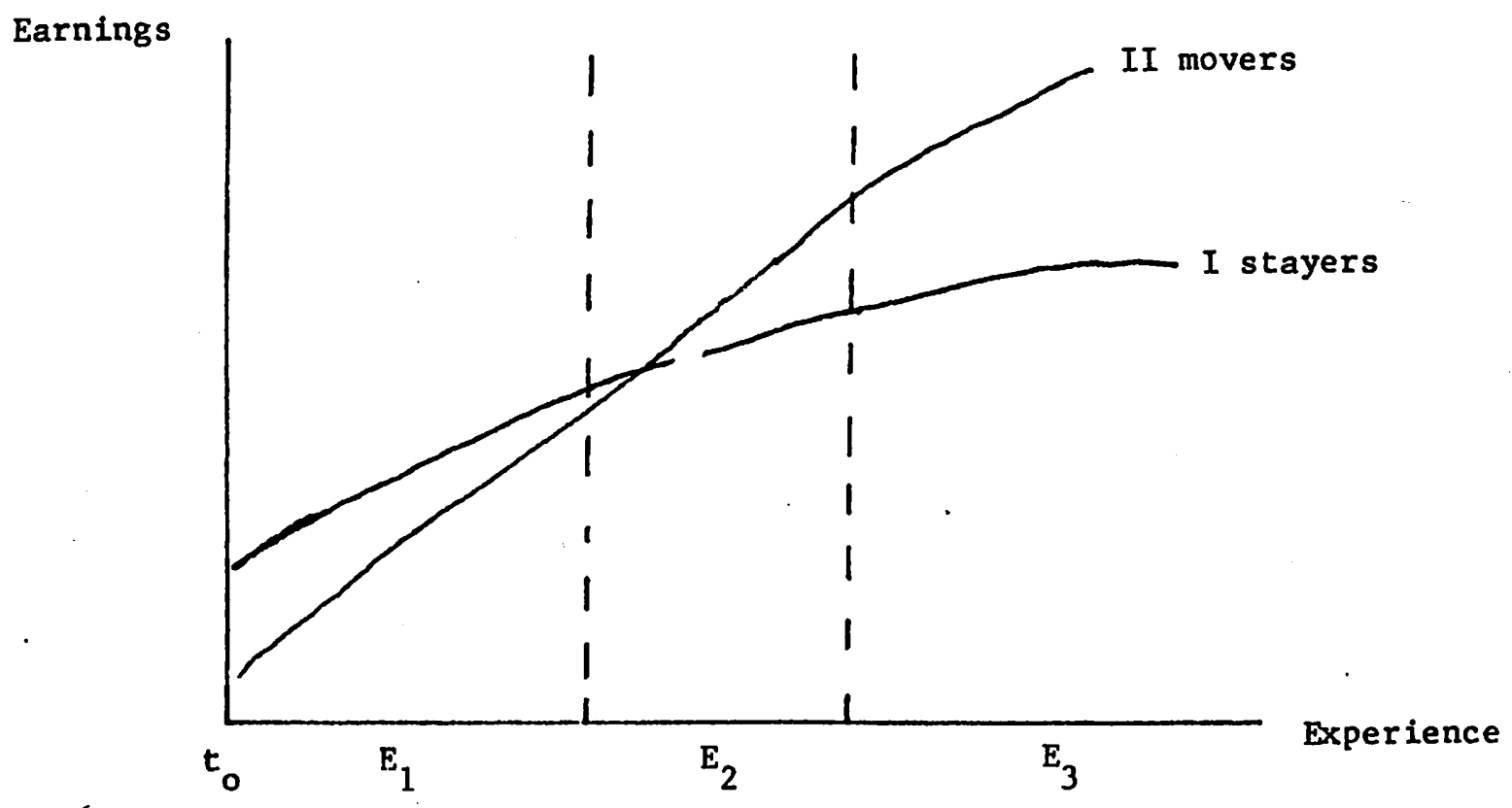

In that case the single observation for individuals with experience $E_{1}$ would tend to overestimate stayer's permanent income relative to a mover's, and viceversa for the individual with experience $E_{3} \cdot$ of course it is not necessary that 
the mover profile is typically steeper than the stayer profile exclusive of moving cost. If the profiles are reversed, $E_{1}$ stayers have underestimated permanent income relative to movers and vice-versa for $E_{3}$. If there were no cohort effects, this problem could be overcome by computing a permanent wage from the lifetime wage profile implied by the cross-section estimates. In view of the likely presence of such effects, the wage regressions were computed separately for different experience cohorts.

\section{The Data}

The 1/100 individual file of the 1971 Canadian Census was used to estimate the model outlined in the previous section. These data provide information on the individual's location in 1971 and also the province in which they completed their highest grade of elementary or secondary schooling. In this study an individual is defined as a lifetime migrant if his province of residence in 1971 differed from that in which he completed schooling. The sample was restricted to Canadian-born males ${ }^{6}$ age 15-64 (in 1971) who completed their schooling in one of the nine provinces (excluding PEI). In order to obtain measures of wage rates we restricted the sample to paid workers in the civilian labour force, reporting positive usual hours, weeks of work and income from wages and salaries in 1970; and whose main source of income was not from self-employment.

At this point the limitations and advantages of these data should be emphasized. First, as already mentioned, the Census data provide only one wage observation per individual, so that we are unable to allow for individual differences in wage growth rates, since this would require panel data. Second, as Grant and Vanderkamp (1980) point out, we are unable to identify migrants who moved more than once since completing schooling and we have only limited 
information on the timing of migration or on the identity of return migrants. 7 However an important advantage to the Census data is that the migrant sample is not restricted to individuals migrating within the recent past, so that the estimated wages of movers reflect the lifetime payoffs to migration, and are less likely to be confounded by transitory wage components associated with the transition period following a move. [See Marr and Millerd (1978), Grant and Vanderkamp (1980)]. In addition the Census data provide measures of education, post-school training, language and other chacteristics, which are not available in other samples. We therefore include an extended 1ist of 'buman capital' variables in order to control for the possibility that movers possess a greater propensity to invest in all forns of human capital, including migration [Greenrood (1975), Grant and Vanderkanp (1980)].

The resulting sample consists of 32,427 males of whom 4,458 ( $13.75 \%$ ) are interprovincial migrants. The migration flows for this sample are displayed in Table 1 by province of origin. This table shows the dominant patterns of post Wor Id War II interprovincial migration: the Atlantic and Prairie provinces experienced high rates of outmigration, while the two provinces with the highest average incomes (Ontario and B.C.) and Quebec exhibit low rates of outmigration. The major destination of Atlantic and Quebec outmigrants has been Ontario; and that of outmigrants from the Prairie provinces has been B.C. Migrants from Untario have chosen Quebec or B.C. as their major destinations, and those from B.C. either Alberta or Ontario. The substantial migration to Alberta which occurred in the 1970's is not reflected in the 1971 Census data. In addition, Table 1 also indicates 
Table 1

Lifetime Migration Flows by Province of Origin

Province of Origin (At Completion of Schooling)

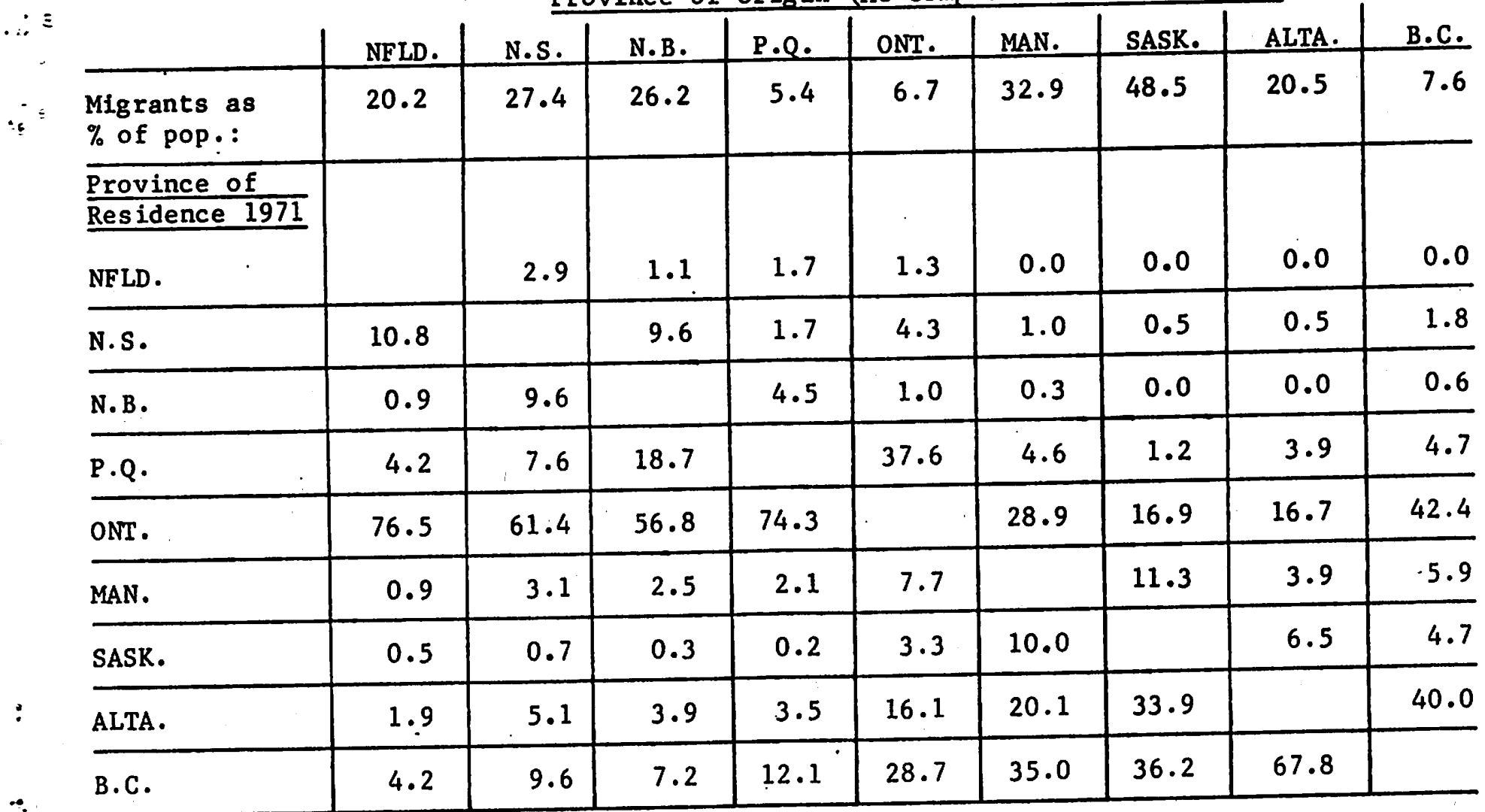

Notes. 1: Row \#1 gives lifetime out-migrants as a of the origin population, e.g., $20.2 \%$ of Individuals who completed schooling in NFLD. were resident in one of the other eight provinces in 1971. In this table identified return migrants (see footnote 7 ) are included with Stayers.

2. The remaining entries give the $\%$ of out-migrants who resided in a particular province in 1971 , e.g., $10.8 \%$ of migrants out of NFLD. resided in N.S., $0.9 \%$ in N.B., etc. Columns may not sum to 100 due to rounding. 
considerable individual diversity--individuals moving from Ontario to the Maritime provinces and from B.C. to the Prairies--counter to the predominant patterns of migration.

Table 2 defines the variables used in the estimation. Since the Census data provide only one observation on each individual we replace our theoretical concept of lifetime 'permanent' wage rates with the individual's hourly wage rate.

4. Estimation and Main Empirical Results

The first stage of the procedure was the estimation of the reduced form probit implied by the reduced form selection index (8). The estimation was carried out separately for two experience categories, 5 to 20 years experience, and $20+$ years experience, and was repeated for each province. 8 Each sample thus consisted of all individuals residing in a given province at the time of completion of highest school grade (origin province) and in a given experience category in 1971. The sample is not pooled across provinces since individuals commencing their 'economic life' in Newfoundland face a different set of location opportunities than those originating in Alberta. The coefficients from the reduced form probit equation ${ }^{9}$ indicate the total effect of the exogenous variables on the probability of moving, both via the wage differential for moving versus staying and via the costs of moving. When the YRSSCH variable is significant (for four provinces) it enters with a positive coefficient, indicating that the more educated are more mobile. 
Table 2

Definitions of Variables

$\therefore$

Migrat1on :

is :

Period of Migration:

Wage :

Schooling :

Degree :

Age :

Experience:

Post-school

Training :

.. Language :

Marital status :

Family Size:

$\because$ Location:
1: if 1971 province of residence differs from province of residence at completion of highest grade of primary or secondar schooling; 0 : otherwise

MIG

1: if migration occurred within last five years (i.e., provence of residence in 1966 differed from that of 1971);

0 : otherwise

RECNIMIG

Natural $\log$ of hourly wage in $10 \notin$ units. Wage $=$ (Income from wages and salaries + Income from self-employment) $\div$ (Usual hours worked $x$ weeks worked in 1970)

\&nWAGE

Level of schooling $=$ highest grade of schooling completed

1: if individual possess a university degree; 0 : otherwise Age and its square

Labour market experience $=\mathrm{AGE}-\mathrm{SCH}-6$ and its square

(i) Dummy variables were coded 1 if an individual had completed a full-time apprenticeship or vocational training program of at least three months duration; 0 : otherwise

(ii) Length of full-time apprenticeship or vocational trainting program

(i) French 1: if language of home is French, unable to speak English; 0 : otherwise

FR

(ii) Bilingual-French 1 : if language of home is French and able to speak English; 0 : otherwise

(iii) Bilingual-English 1 : if language of home is English and able to speak French; 0: otherwise

Reference group is language of home is English, and unable to speak French.

(i) Married 1: if either married spouse present or married spouse absent; 0 : otherwise

MARRIED

(ii) Widowed, divorced or separated dummy variable 1 for any of these categories; $0:$ otherwise

WDIVSEP

Reference group is single, $i . e .$, never married.

Number of persons in the Census family of which individual is a

FAMSIZE member.

(i) Dummy variable for provence of present location

NFLD-BC

(ii) Urban/Rural location dummy variables for 1971 residence: in city/town pop. $<30,000$

Rural non-farm residence

Farm residence

TOWN

RNF

FARM

Reference group: 1971 residence in city/town pop. $z 30,000$ 
Table 2: Definitions of Variable (cont'd.)

Family Background and Ability:
Dummy variables :

(1) Ethnic or cultural background on father's side Jewish (0 otherwise)

(ii) Individual's religion Roman Catholic (0 otherwise)

(iii) Both parents foreign born

(iv) Father (only) foreign born

(v) Mother (only) foreign born

Reference group: both parents Canadian born.
CATH

Mneumonic

\section{FBPB}

FBPF

FBPM 
An important exception is Quebec where greater education reduces the mobility of francophones (FR or BILFR). The remaining 'human capital' and postschool training variables are rarely significant. The language coefficients display a consistent pattern: French-speakers and both bilingual groups (BILENG and BILFR) are more likely to migrate out of English Canada, and are less likely to migrate out of Quebec, as compared to the ENG reference group. The AGE and AGESQ variables are often significant and when they are, the AGE coefficient is positive and that on AGESQ is negative. The negative coefficient on AGESQ indicates that the marginal propensity to migrate diminishes with age, consistent with the human capital model of migration. Since the time interval between the completion of schooling and 1971 increases with age the probability of ever having migrated is expected to increase with age. However on the other hand, a secular increase in the availability of information concerning distant job markets and reductions in moving costs would tend to increase the migration of younger cohorts. The observed age-migration pattern may be the net outcome of these offsetting forces.

Family size--a determinant of the cost of moving--enters with a significant negative coefficient for the younger experience group in all provinces (except SASK.). For the older experience group this variable is significant less often, presumably because for this age group the current size of the census family is less adequate as a measure of family size at the time of the decision to move. When the MARRIED variable is significant it enters with a positive coefficient. This finding appears counter-intuitive since married couples are more likely to include tied stayers than unattached individuals (Mincer 1978). However, since the regression holds family size constant, the MARRIED coefficient reflects a partial, rather than gross correlation. Second, as Mincer has pointed out (1978, p. 760) single individuals, as members of families headed by their parents, may also be tied stayers. 
For many provinces urban/rural location is an important determinant of migration. For most provinces (except P.Q. and ALTA.) Town or Rural non-farm (RNF) residence is associated with reduced mobility. In addition, for a number of provinces Farm residence is associated with reduced mobility. However, the interpretation of these coefficients is complicated by the fact that we are using end-of-period (1971) location as a proxy for beginning of period urban/rural location, due to the absence of this latter information. The remaining proxies for 'ability' and family background are rarely significant and do not display a consistent sign pattern across provinces.

These reduced form probit results were used to calculate $\lambda_{a i}$ and $\lambda_{b i}$ for inclusion in wage generating functions estimated separately for each origin province and experience group, and for movers and stayers. The coefficients obtained on $\lambda_{a i}$ and $\lambda_{b i}$ provide us with information on whether there is positive or negative selection bias in the mover or stayer categories-1.e., they indicate whether, for example, a stayer in the origin province, cet. par., has origin province earnings above the average taken over both movers and stayers, whether a mover from origin b earns more cet. par. in his destination than an individual who remained in $b$ would have, had he moved, etc. The empirical specification for the wage equations estimated for stayers and movers separately was as follows: for stayers, lnWAGE was regressed on $\lambda_{b}$ and $x_{b}$ where:

$X_{b}=$ [YRSSCH, EXPR, EXPRSQ, DEGREE, APPTR, VOCTR, LENAPP, LENVOC, FR, BILFR, BILENG, TOWN, RNF, FARM, JEW, CATH, FBPB, FBPF; FBPM]

For movers enWAGE was regressed on $\lambda_{a}$ and $x_{a}$ where

$x_{a}=$ [same variables as $X_{b}$ plus RECNTMIG and dumny variables for province of migration] 
As noted in Section 2, the coefficient vectors $\beta_{a}$ and $\beta_{b}$ are permitted to differ, allowing different rates of return to various characteristics in different provinces. In addition some further control variables are added to the movers.equation. In the absence of more complete information on the date of migration, we introduce a dumny variable for migration within the previous five years (RECNTMIG). Recent migrants are expected to earn less than earlier migrants with the same characteristics (Grant and Vanderkamp, 1980). Since the cost of living differs widely across provinces we introduce dummy variables for provinces other than the major province of destination, to allow these differences to be reflected in nominal wage rates.

The estimated wage equations were similar to the standard results in the literature with schooling and experience figuring as variables of primary importance. The pattern of rates of return differences on the schooling variable across provinces followed closely the pattern reported by Chiswick (1974). of particular interest here are the estimates of selectivity into the movers and stayers group, and in order to focus on this only the coefficients on $\lambda_{a 1}$ and $\lambda_{b i}$ are reported in Table 3 below. Our results suggest that self-selection is an important phenomenon in inter-provincial migration. With the exception of NFLD, we find evidence of sample selection bias for at least one experience group, in the wage equation of either movers or stayers for all provinces. For the experience group 5-20 years, selection into at least one of the categories is significant in New Brunswick, Ontario, Alberta and francophones in Quebec. For the experience $20+$ years category all provinces show significant selection bias except Newfoundland, New Brunswick and Ontario. For the younger experience group, the estimated coefficient on $\lambda_{a}$ is either unsignificantly different from zero or significantly negative. Since $\lambda_{a i}<0$, this implies a positive selection into the movers group--i.e., the people who actually moved out of origin $b$ earned more, cet. par. in their destination than the stayers in origin b would have done had they also moved. The estimated coefficients on $\lambda_{b}$ for the younger 
Table 3

Estimates of Sclection Bias

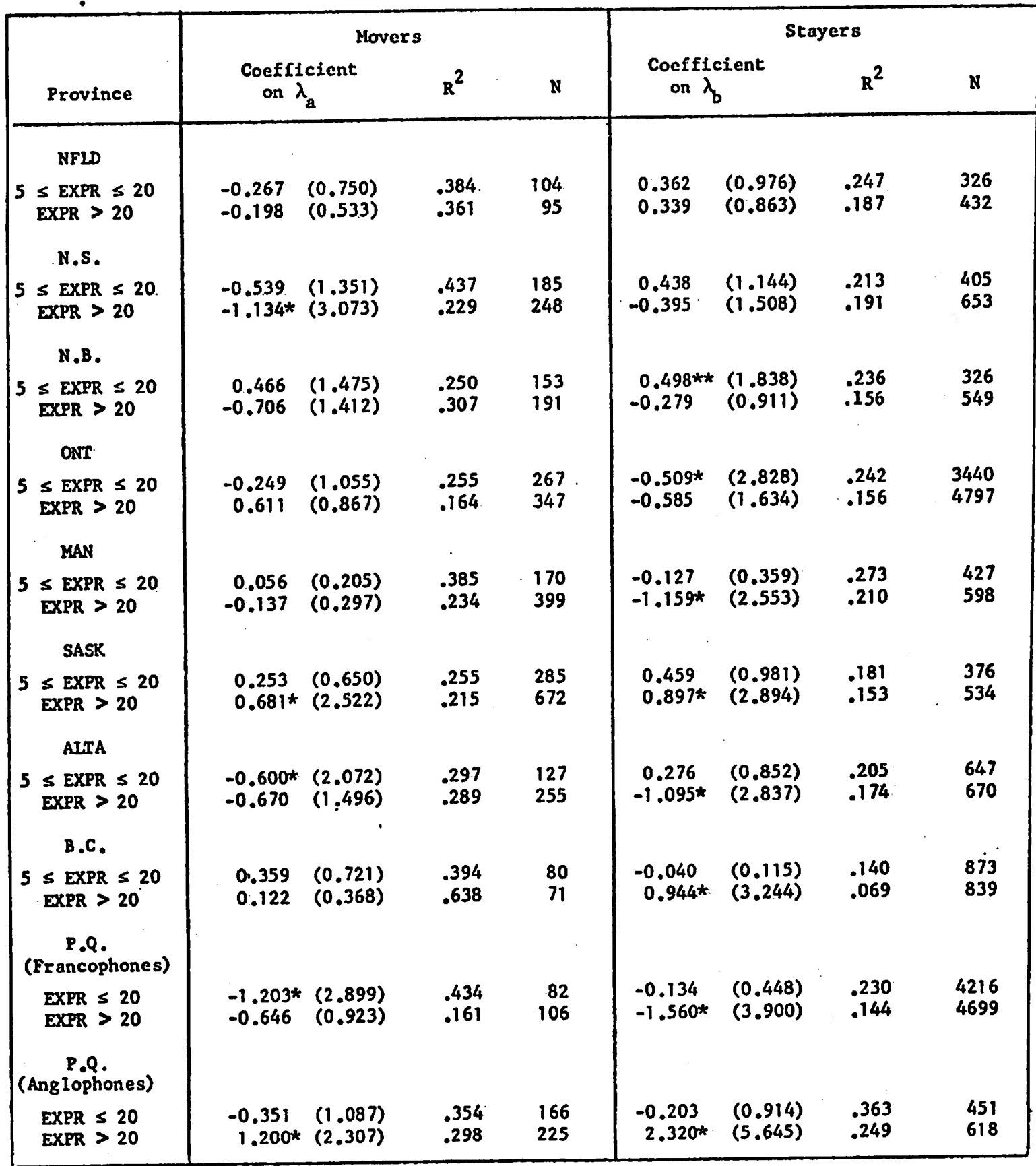

Notes:

* significant at $\leq 5 \%$ level.

** significant at $\leq 10 \%$ level.

The $P . Q$. sample was split into anglophones and francophones; the resulting sample size for the lower experience group was very small so that those with less than 5 years experience were included in the sample for P.Q. 
group and for both $\lambda_{a}$ and $\lambda_{b}$ for the older experience group show no clear sign pattern.

The model of Section 2 states that an individual will move from b to $a$ when his permanent income in a exceeds that in $b$ net of moving costs. The estimated coefficients from the wage equations allow us to compute "permanent wage" in both locations for each individual. 11 These predicted wages are the input into the final stage of the procedure--estimation of the parameters of the structural probit implied by equation (2) in Section 2 above. Before reporting the results in the last step of the procedure, some comments should be made on the predicted wages from the estimated coefficients in the separate move and stayer wage equations. First, any differences in cost-of-living across provinces are assumed to result on compensating differentials in wage rates. For the purposes of analysis, therefore, we choose a reference province (the major destination province of movers) and then for all individuals from an origin province, $b$, we compute the nominal permanent wage they could obtain in $b$ and the nominal permanent wage they could obtain in the reference province. The former is obtained by applying the coefficients $\left(\beta_{b}\right)$ obtained in the "stayers" wage regression to each individual's characteristics. The latter is obtained by applying the coefficients obtained in the "movers" wage regression to each individual's characteristics, where the dumny variables for destination province and RECNTMIG are both set to zero for all individuals. Any difference in cost of living between origin and reference destination province will be constant across individuals so that an increase across individuals in the computed nominal wage will imply an increase in the real wage. For both of these potential wage calculations we have retained information on the urban/farm location of each individual and have used it as a permanent characteristic of the individuals rather than using a compensating differentials approach and defining a reference urban/farm location. The approach we have taken assumes 
that via specific investments, individuals will tend to retain their urban/farm - location characteristic whether they are movers or stayers.

The structural probit implied by equation (2) was estimated in two forms. First, the differences between predicted wages in the (reference) destination and origin province (lny ${ }_{a i}-\operatorname{lny}_{b i}$ ) was included directly having a presumptive positive sign; second, lny ${ }_{a i}$ and $\ell^{n} y_{b i}$ were included separately with predicted positive and negative signs, respectively. The probit also includes the cost of moving term $c_{1}$, given by equation (5):

$$
c_{i}=z_{i} \delta+u_{c i} \quad \text { (5) repeated. }
$$

The empirical specification for $z_{i}$ is:

$$
\mathrm{Z}=\text { (FAMSIZE, MARRIED, WDIVSEP, YRSSCH, FR, BILFR, BILENG, }
$$
JEW, CATH, FBPB, FBPF, FBPM)

This specification embodies some important identifying restrictions, in that the cost of moving is assumed independent of the training variables and the possession of a degree. These variables are assumed to influence migration only via their effects on wage rates in various provinces. In addition urban/ rural location--which represents the individual's location at the end of the decision period--is excluded from $Z$ and influences migration only via interprovincial differences in wage rates. The results of the probit estimation are reported in Table 4 below.

Table 4 reports 18 probit equations, representing two alternative specifications of the wage variables, for each of the nine provinces. ${ }^{12}$ Let. us first examine the results relating to the wage variables, which represent the crucial test of the human capital migration model. When the wage variable is entered in first difference form (DLNW in the odd numbered columns) it is significant at the $5 \%$ level (or better) in 5 of the 9 cases. ${ }^{13}$ with the exception of Ontario (column 9) all the coefficients have the predicted positive sign. 


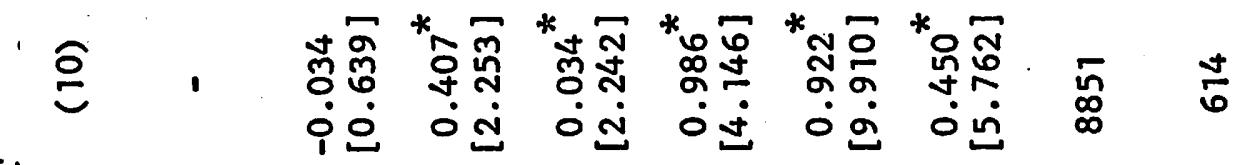
昌

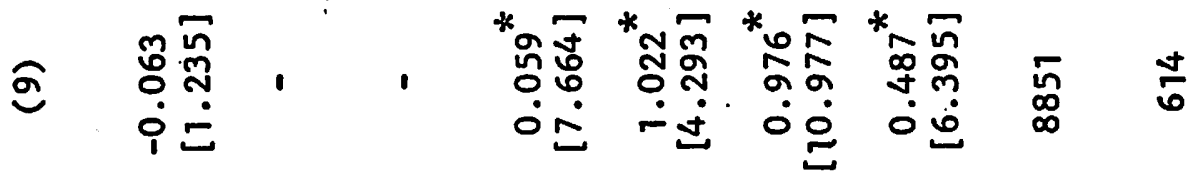

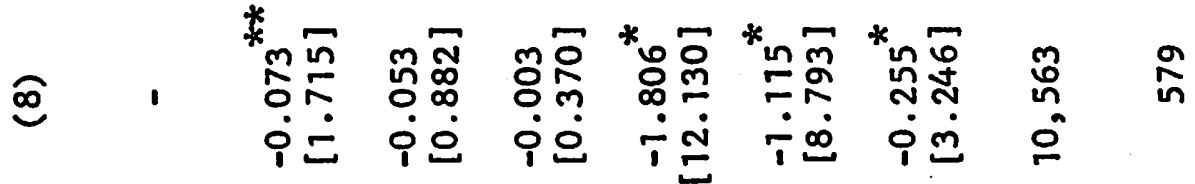

品

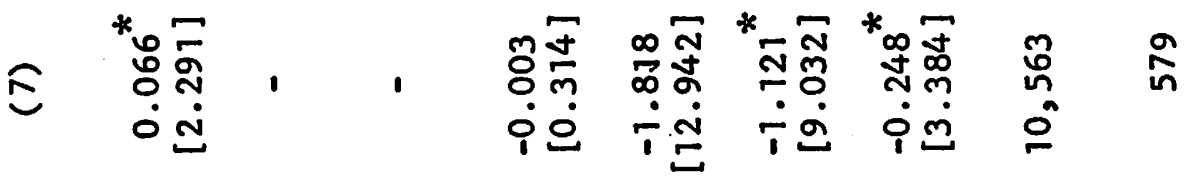

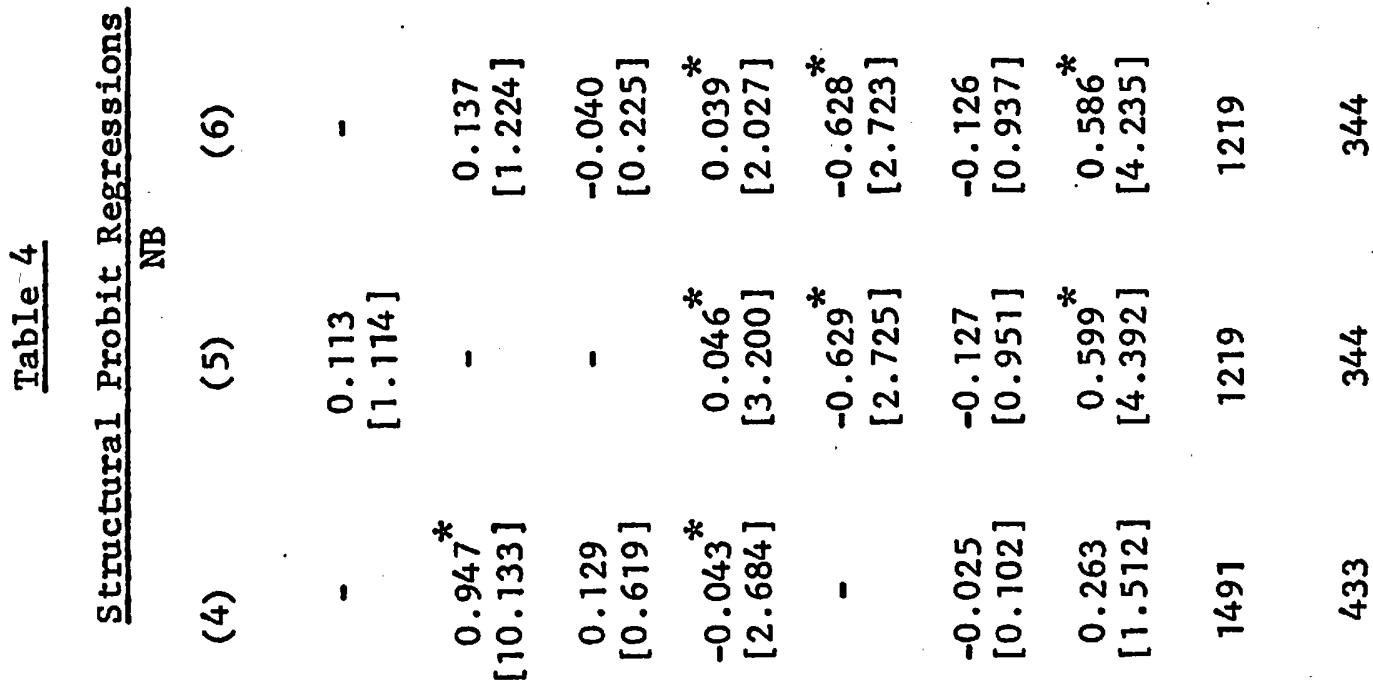

号

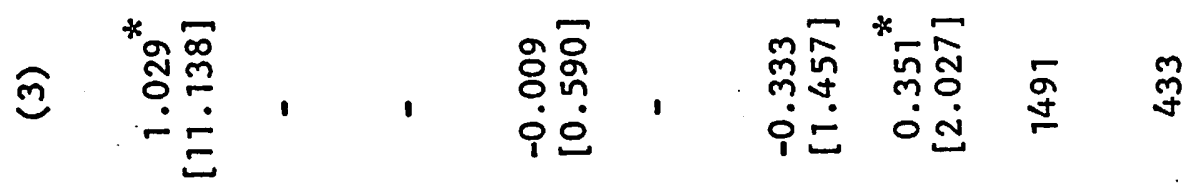

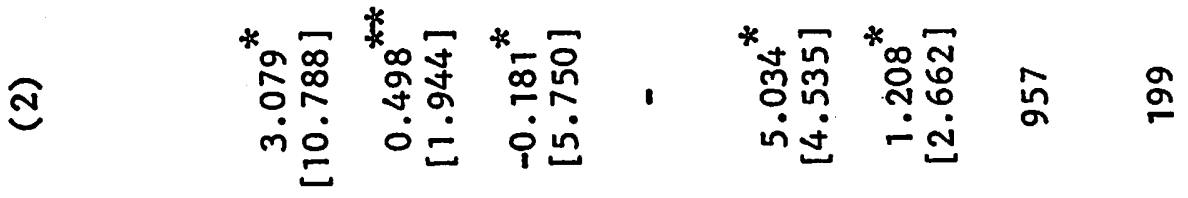

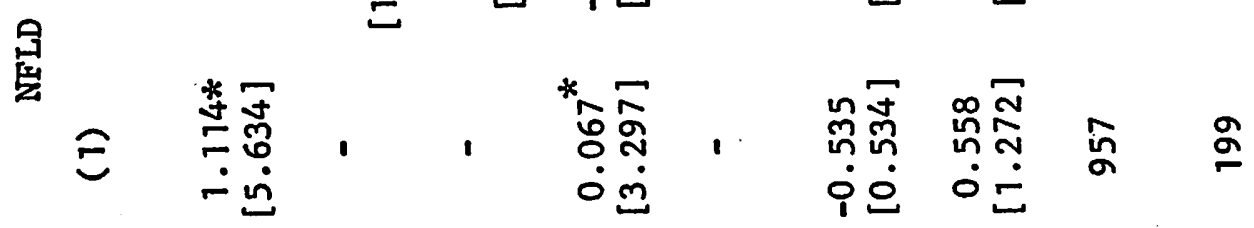

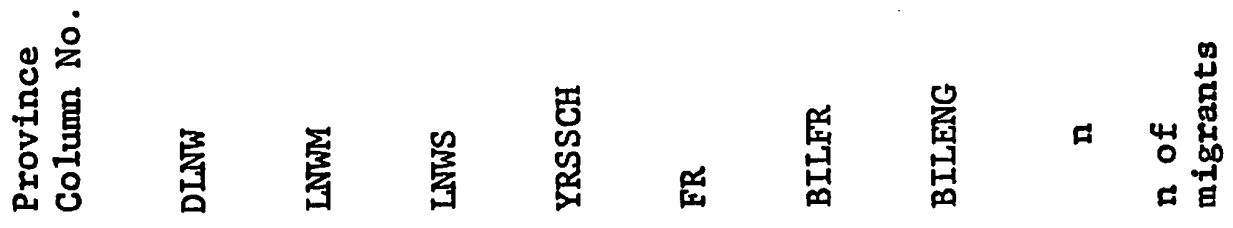




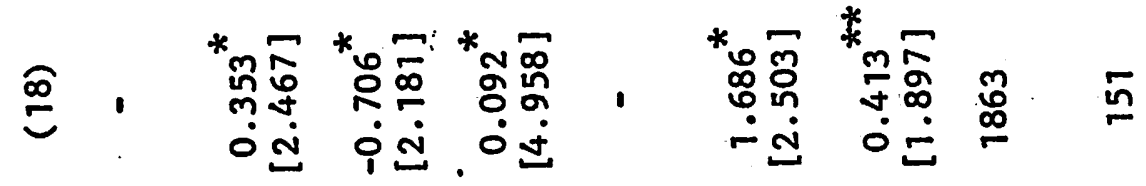

ర్m

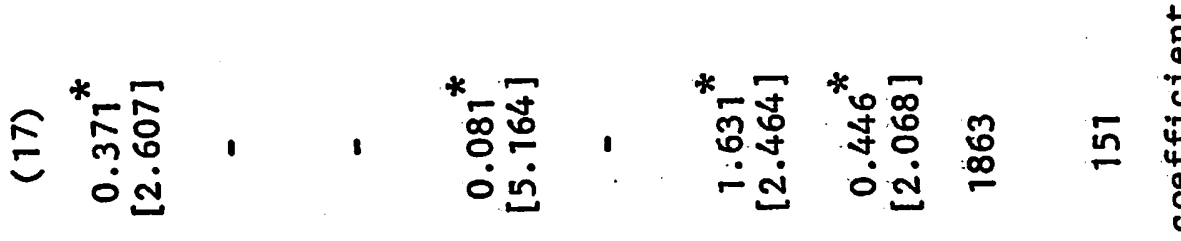

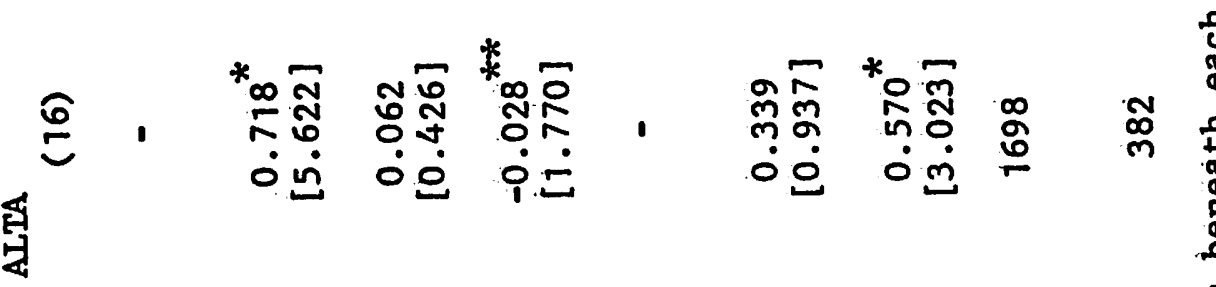

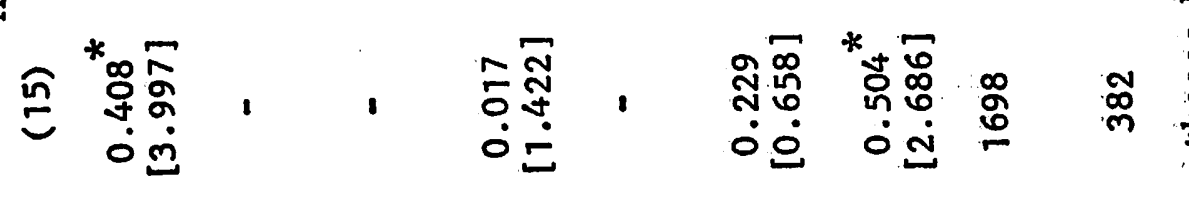

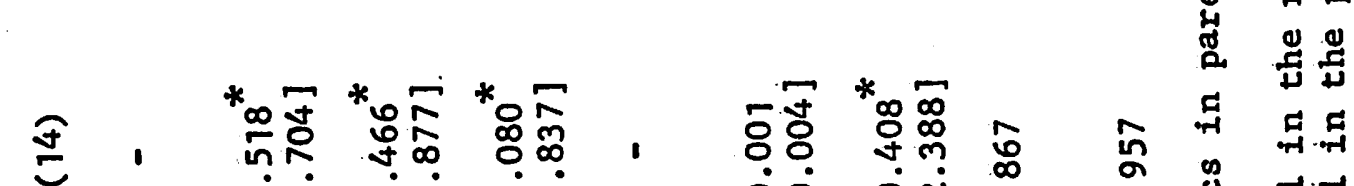

盯

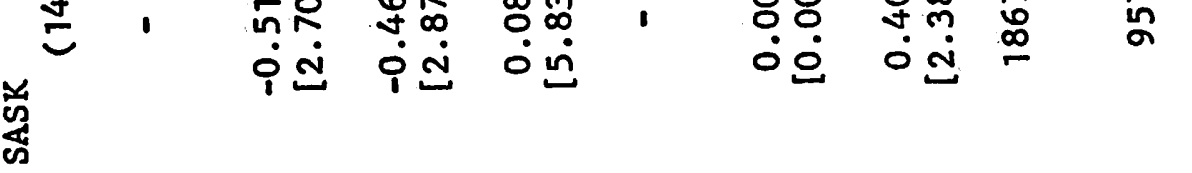

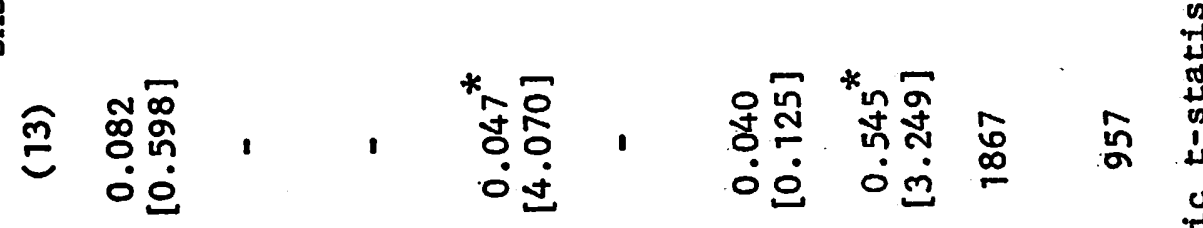

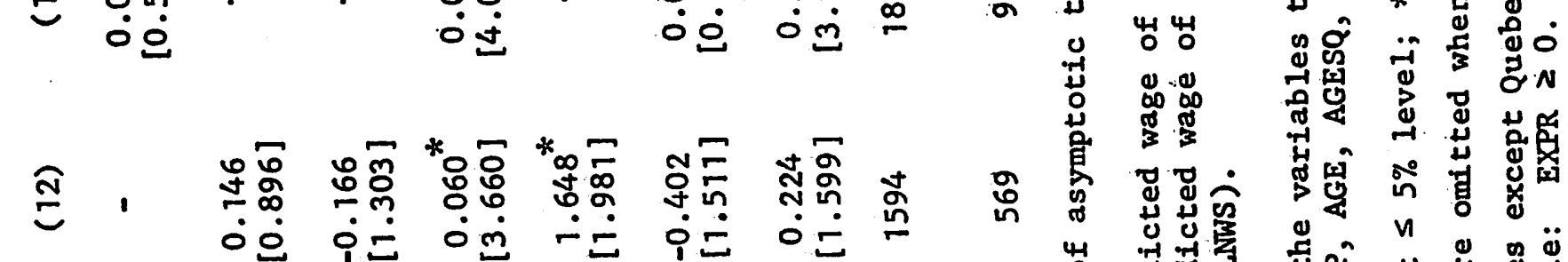

茨

ì

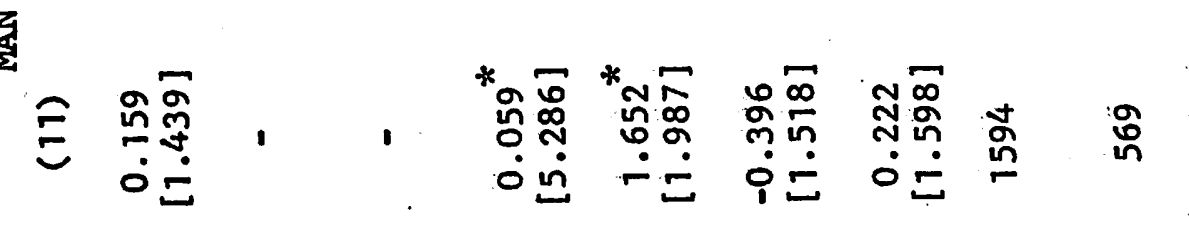

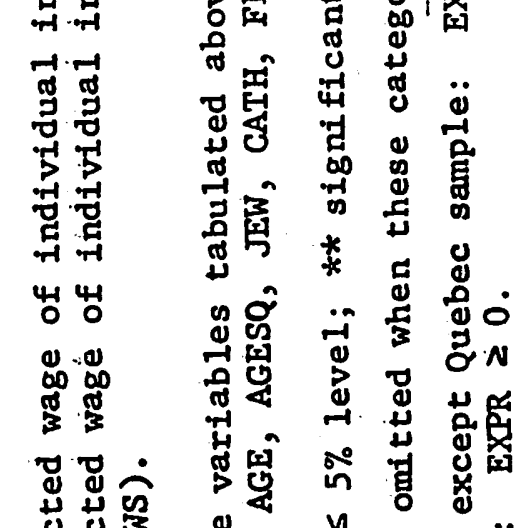

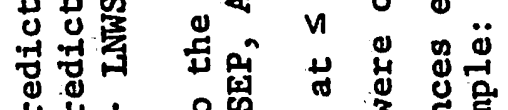

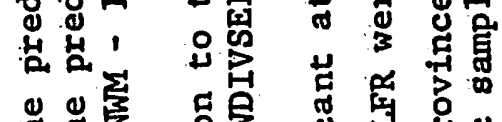

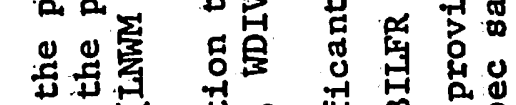

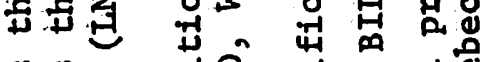

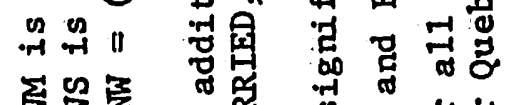

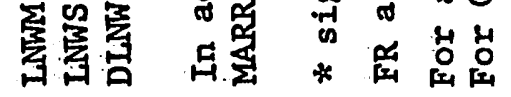

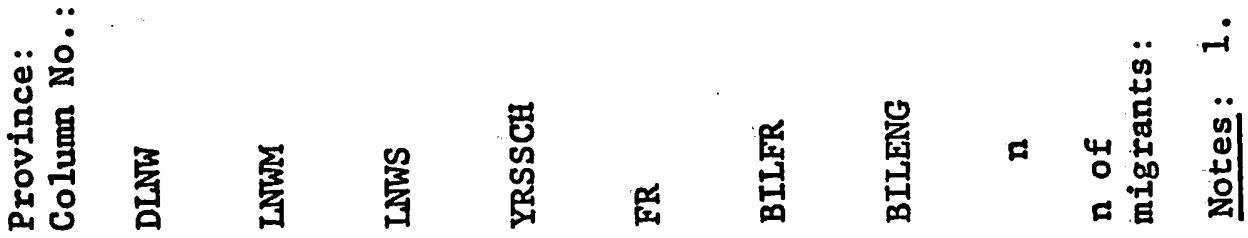

$\dot{N} \quad \ddot{m} \quad \dot{j} \dot{0}$ 
Furthermore, when the structural probit is estimated separately for the two experience groups (results not reported here), this wage variable is positive and significant for at least one of the two experience groups for all provinces except Ontario. Subject to the caveat concerning significance tests (see footnote 13), and our identifying restrictions, this represents impressive evidence in favour of the human capital model.

When the predicted wages if an individual had moved and stayed are entered separately (even numbered columns) the wage in the destination province (LNWM) is significant in 6 of the 9 regressions. With the exception of Saskatchewan (column 14), this variable, when significant has the predicted positive sign, indicating that the higher, the wage an individual could obtain in the destination province the greater the probability of migration (ceteris paribus). Thus in over $50 \%$ of the cases the results support the theoretical prediction.

The prediction of the wage an individual could obtain in the origin province (LNWS) performs less well. It is significant in 4 cases and in only 2 cases does it enter significantly with the predicted negative sign. At the micro level these results confirm those obtained in earlier aggregate studies: a higher wage in a province encourages in-migration, while there has been somewhat weaker support in this study and macro studies for the prediction that a higher wage reduces out-migration (Vanderkamp, 1971).

The overall results on the effect of the potential wage variable are more impressive when viewed against the background of the magnitude of the typical wage difference between provinces required to induce the average individual to move. The expected earnings difference between destination and origin province needed to balance the cost of the investment is relatively small, especially when compared with the earnings differential between college and 
high school graduates. Thus, if migration is a marginal decision for most of the individuals in our sample this "small" earnings differential will be harder to detect than the differentials resulting from larger investments such as schooling.

For New Brunswick, Ontario, Manitoba, Saskatchewan and B.C. there is evidence that, holding wages constant, mobility increases with education, due to either improved infarmation or reduced costs of moving. This finding offers some support for the predictions made by Schwartz (1973) . However for NFLD, NS and ALTA the sign of the YRSSCH coefficient is sensitive to the specification of the wage variables. (Quebec is examined separately below.)

Ignoring the effects of language for the moment, the coefficients of the remaining variables entered in the structural probit regressions (not reported in Table 4) require only brief comment, since they duplicate the results reported earlier for the reduced form equations. Family size enters with a negative coefficient. When the probit equation is estimated separately for the two experience groups, this variable is negative and always significant at the $10 \%$ level (or better) for the younger experience group. Family size is thus an important deterrent to mobility, which suggests that the secular decline in family size has resulted in greater geographic mobility. The results for the older experience group offer somewhat weaker evidence in the same direction. When the MARRIED coefficient attains significance it is positive (except for the older experience group of BC origin).. This suggests that (holding family size constant) single individuals (Ilving say with their parents) are more likely to be tied stayers than married males. Alternatively this result may be due to the greater speclalization of married men in the labor market, making them more willing to move for a given wage differential. When the age variables enter significantly, 
they display the quadratic pattern described earlier--the marginal propensity to migrate declines with age. The remaining 'ability' and family background variables are seldom significant and do not display a constant sign pattern across provinces.

\section{Migration and Language}

The language coefficients in the structural probit equations are of interest, since with wages held constant they represent the combined effects of cultural ties, information costs and consumption aspects of location. The results indicate that individuals who only speak the French official language (FR) are more likely to be out-migrants from Ontario and Manitoba than anglophones with the same characteristics (columns 9-12), and are less prone to migrate from Quebec or NB (columns 5-8)--the two provinces with the largest \% francophones. Bilingual francophones are more likely to leave NFLD, ONT and BC and less likely to leave Quebec (columns 7-8). However, the deterrent effect of BILFR on out-migration from Quebec or NB is less than that of FR. Bilingual anglophones are more likely to migrate from many of the provinces in 'English Canada', but less 1ikely to leave Quebec (colums 7-8). These results imply that language influences migration through other channels in addition to wages. Table 5 presents more detailed results for Quebec concerning language and out-migration. Colums 1-4 report separate probit equations for the two language groups in Quebec. The results imply that (holding the monetary returns to migration constant) bilingual francophones are more likely to leave Quebec than monolingual francophones (colums 3-4) and bilingual anglophones are less 1ikely than monolingual anglophones, to be out-migrants (columns 1-2). These results concerning language and migration can be given an information interpretation. A ssuming the acquisition of a second language is causally prior to the migration 


\section{Table 5}

Structural Probit Equations for Quebec Language Groups

\begin{tabular}{|c|c|c|c|c|}
\hline \multirow{2}{*}{$\begin{array}{l}\text { Language Group.: } \\
\text { Column No.: }\end{array}$} & \multicolumn{2}{|c|}{ ENGLISH } & \multicolumn{2}{|c|}{ FRENCH } \\
\hline & (1) & (2) & (3) & (4) \\
\hline DLNW & $\begin{array}{l}-0.010 \\
{[0.127]}\end{array}$ & - & $\begin{array}{c}0.156^{*} \\
{[2.662]}\end{array}$ & - \\
\hline LNWM & - & $\begin{array}{l}-0.217^{*} \\
{[2.828]}\end{array}$ & - & $\begin{array}{c}0.166^{*} \\
{[2.782]}\end{array}$ \\
\hline LNWS & - & $\begin{array}{l}-0.213^{*} \\
{[2.642]}\end{array}$ & - & $\begin{array}{c}0.180 \\
{[0.528]}\end{array}$ \\
\hline YRSSCH & $\begin{array}{c}0.046^{\star} \\
{[3.593]}\end{array}$ & $\begin{array}{l}0.066^{*} \\
{[4.633]}\end{array}$ & $\begin{array}{l}-0.049^{*} \\
{[3.775]}\end{array}$ & $\begin{array}{l}-0.063^{*} \\
{[3.342]}\end{array}$ \\
\hline FR & - & - & - & - \\
\hline BILFR & - & - & $\begin{array}{c}0.773^{*} \\
{[9.782]}\end{array}$ & $\begin{array}{c}0.712^{*} \\
{[7.129]}\end{array}$ \\
\hline BILENG & $\begin{array}{l}-0.319^{*} \\
{[4.254]}\end{array}$ & $\begin{array}{l}-0.188^{*} \\
{[2.225]}\end{array}$ & - & - \\
\hline n: & 1460 & 1460 & 9103 & 9103 \\
\hline $\begin{array}{l}\text { n of } \\
\text { migrants: }\end{array}$ & 391 & 391 & 188 & 188 \\
\hline
\end{tabular}

Notes: 1. See notes $1-4,6$, Table 4 .

2. Columns 1-2 language reference group is ENG Columns 3-4 language reference group is FR. 
decision. $^{14}$ One of the payoffs to becoming bilingual may be the increased availability of information concerning job offers in labor markets in which the second language is used. For given wage rate differentials the reduction in search costs would lead to greater in-migration towards that labor market and reduced out-migration away from that labor market. The observation that bilingual francophones are less likely to be out-migrants from English Canada (ONT and MAN) and more likely to be out-migrants from Quebec or NB (as compared to FR) is consistent with this interpretation. Also the observation that BILENG increases out-migration from English Canada, but reduces out-migration from Quebec conforms to this interpretation. Our results therefore imply that increased bilingualism would result in increased out-migration of majority language groups and decreased out-migration of minority language groups, holding wage differentials constant.

Also of interest are the contrasting effects of education on the mobility of the two language groups. More education increases the mobility of anglophones (columns 1-2), a result consistent with the findings for other provinces. However, . greater education reduces the mobility of francophones. Furthermore this finding seems to be restricted to Quebec; in similar probit regressions on francophones of Ontario origin (results not presented here) it was found that education increased the out-migration of the younger experience group. Neither the education-information hypothesis nor the effects of education on moving costs imply such a negative coefficient. One possible "explanation" is that greater education on the part of francophones increases the demand for cultural activities conducted in French. Such consumption activities may be more costly to purchase in English Canada. 15 


\section{Conclusion}

We have specified and estimated a model of individual migration behavior. In contrast to earlier empirical studies which have used data on interprovincial migration to test the human capital migration model we use individual data. In addition we have emphasized the importance of taking account of heterogeneity in the population of potential migrants. Since migration is assumed to be the outcome of maximizing behavior individuals will select themselves into mover or stayer categories, resulting in biased estimates of the returns to migration. The econometric methodology employed in this paper takes into account this self-selection process and permits us to obtain unbiased estimates of individual's opportunity wages as movers or stayers. In the empirical exercise carried out here we find evidence of such a selection process. The estimated returns to migration were introduced into a structural probit regression, along with factors influencing the cost of moving. This structural equation, determining the probability that an individual will move, represents the micro counterpart to the migration flow equations estimated in aggregate studies.

The empirical results of an analysis of ' 1 ifetime' migration behavior using 1971 Canadian Census data offer strong support for the human capital model. For all the provinces except Ontario, we find evidence that wage rates in the origin and destination province influence migration in the predicted direction. Given the shortcomings of the data which provide only one wage observation per individual, we find these results encouraging. With panel data on wages we would be able to expand the empirical model to incorporate heterogeneity across individuals in growth rates of wages. More detailed information on the timing of migration would enable us to allow for differences in wageexperience profiles before and after migration. Information on migrants making 
multiple and return moves could also be incorporated although the statistical model would increase in complexity. The census data do not allow us to incorporate these refinements, although we have every reason to believe that they are important considerations in lifetime migration behavior.

Other results are of interest in a Canadian context. Holding the monetary returns to migration constant, language. still exerts an important influence on migration. Individuals who speak only French are more 1ikely to leave Ontario and Manitoba and less likely to leave Quebec and New Brunswick. Bilingual individuals of both language groups are more likely to be out-migrants from English Canada, but less likely to leave Quebec. This suggests that one of the returns to bilingualism comes in the form of increased information concerning wages in the job markets in which the second language is predominant. For many provinces we find that education increases mobility. However an important exception is Quebec francophones whose mobility was found to be inversely related to education. This finding is difficult to rationalize in terms of the usual hypotheses concerning education and migration. 
FOO TNOTES

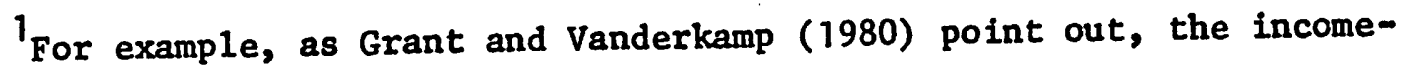
distance tradeoff estimates obtained from micro data differ substantially from the earlier estimates obtained by Vanderkamp (1971) using aggregate data.

2 The same problem arises in the interpretation of measures of labor supply; see Heckman (1978).

${ }^{3}$ The equations estimated in these two studies differ substantially. Marr and Millerd (1978) include a dumy variable for migrants, which implicitly assumes that the returns to migration are the same for all individuals in the origin population. Thus the observation that some individuals move while others stay must be due to differences in the costs of migration. In contrast Grant and Vanderkamp (1980) include interaction terms between migration and individual's characteristics, so that the returns to migration are permitted to differ across individuals.

4 Nakosteen and Zimmer (1980) apply the same econometric methodology to analyze migration in the U.S. Continuous Work History Sample. However, the model which they estimate appears to be misspecified. Borjas and Rosen (1979) examine job mobility and Polachek and Horvath (1977) employ an alternative 'mixed logit' approach to analyze migration patterns in the Michigan Panel Study of Income Dynamics data.

5 Such a probit may be interpreted as follows: of all individuals with characteristics $x_{i}$, only a fraction have the appropriate value of $\epsilon_{i}$ which will make them move. For the investigator this fraction. is the probability 
that an individual with characteristics $x_{i}$ will move, because the investigator knows only the distribution of $\epsilon_{1}$. For each individual the decision to move or not to move has no probabilistic aspect since each individual knows his own realization of $\varepsilon_{1}$.

We restrict the sample to males, since the incidence of tied movers and stayers is expected to be of less importance for males given their greater attachment to the labor market (see Mincer 1978). An analysis of migration by females would also have to incorporate a second sample selection problem since a sizable fraction of women are non-labor force participants.

${ }^{7}$ The data provide information on whether the individual resided in the same or different province in 1966 as compared to 1971. Since the province of 1966 residence is not reported we are unable to ascertain whether a 1966-71 move on the part of migrants represented an initial or higher order move.

We have used this same information to identify recent return migrants (i.e., those who resided in 1971 in the province where they completed schooling, but resided in a different province in 1966). These cases, representing $1.5 \%$ of the original sample, have been eliminated from the sample used in the subsequent regressions.

${ }^{8}$ Preliminary estimates of the wage regressions indicated the need for separate wage regressions for different experience categories. For Quebec the samples were also subdivided into francophones and anglophones. Since the resulting subsamples of movers were quite small, due to the low rate of out-migration from Quebec, the lower experience group for this province was extended to include $0 \rightarrow 5$ years experience. 
${ }^{9}$ Not reported.

10 Estimating separated wage regressions for the different experience groups allows the payoffs to wage-generating characteristics to differ over the life-cycle and across cohorts, as suggested by earlier studies [see, for example, Daymont and Houser (1976)]. Our results are consistent with such differences, for example, we find the rate of return to schooling to be systematically lower for older workers.

11 As indicated in equation (11) the "permanent wages" in origin and destination provinces were calculated by applying the estimated coefficients $\left(\beta_{\alpha}\right.$ and $\left.\beta_{b}\right)$ to the individual's characteristics $\left(X_{i}\right)$. We thus attribute the deviation between the individual's observed wage and the estimated wage to transitory factors, including measurement error. Again in the absence of panel data we are unable to distinguish permanent and transitory components of each individual's residual.

We calculate the predicted wage at the observed level of experience and include age in the subsequent probit equation. We have also experimented with calculating the predicted wage at a common level of experience for all individuals. The results correspond fairly closely with those we report here.

12 The reported regressions pool the two experience subsamples, on the assumption that cohort effects are not of major importance for the variables that affect migration other than via wage rates. We have also estimated the structural probit equations separately for each experience group. The results (available on request) are broadly consistent with those reported in Table 4 .

${ }^{13}$ In the context of the structural probit regressions the results of significance tests should be interpreted with caution since, because the wage variables are predicted values, the t-statistics are upward biased. Although 
in principle a procedure exists for calculating the unbiased t-statistics this is a major computational exercise (see Lee 1977). A program to calculate these statistics is not currently available to us. We therefore follow previous authors [e.g., Lee 1978, Borjas and Rosen 1979] in reporting the uncorrected statistics.

${ }^{14}$ The acquisition of a second language may occur after migration. However, monolingual individuals considering changing linguistic job markets should take account of the returns and costs of learning a second language. Given the wage rate differential individuals with a lower cost (greater ability) will become bilingual. Thus the language variables can be interpreted at a more basic level as capturing differences in the costs (abilities) of individuals becoming bilingual.

${ }^{15}$ Given the concentration of the Quebec-English in Montreal a reverse argument may not apply to English-language in-migrants to Quebec since their likely destination is also Montreal. 


\section{REFERENCES}

Borjas, G. and S. Rosen, "Income Prospects and the Job Mobility of Younger Men," Research Report No. 7920, mimeo, University of Chicago (1979).

Chiswick, Barry R., "Sons of Immigrants: Are they at an Earnings Disadvantage?" AER Papers and Proceedings, Vol. 67, No. 1 (February 1977), pp. 376-80. , Income Inequality: Regional Analysis Within a Human Capital Framework, NBER Columbia University Press, 1976.

Courchene, Thomas J., "Interprovincial Migration and Economic Adjustment," CJE, Vol. 3 (1970). - Migration, Income and Employment: Canada 1965-68, Montreal, C.D. Howe Research Institute (1974).

Daymont, Thomas N. and Robert N. Houser, "Schooling, Ability and Earnings: CrossSectional Findings 8 to 14 Years After High School Graduation," mimeo, University of Wisconsin (May 1976).

Grant, E. Kenneth and John Vanderkamp, The Economic Causes and Effects of Migration: Canada 1965-71, Economic Council of Canada (Ottawa, Information Canada), 1976.

, "The Effects of Migration on Income: A Micro Study with Canadian Data 1965-71," CJE, Vol. 13, No. 3 (August 1980), pp. 381-406.

Greenwood, Michael, "Research on Internal Migration in the United States:

A Survey," Journal of Economic Literature, Vol. 13 (1975), pp. 397-433. Greeley, Andrew, Ethnicity, Denomination and Inequality, Beverly Hills, Calif., Sage, 1976. 
Heckman, James J., "The Common Structure of Statistical Models of Truncation, Self Selection and Limited Dependent Variables, and a simple Estimator for Such Models," The Annals of Economic and Social Measurement, Vol. 5: (1976), pp. 475-492.

, "Sample Selection Bias as a Specification Error," Econometrica, Vo1. 47, No. 1 (Jan. 1979), pp. 153-62.

, "A Partial Survey of Recent Research on the Labor Supply of Married Women," American Economic Review; Papers and Proceedings, 68, No. 2, (May 1978), Pp. 200-207.

Heckman, James $\mathrm{J}$. and Solcman Polachek, "Empirical Evidence on the Functional Form of the Earnings-Schooling Relationship," JASA, Vol. 69 (1974), pp. $350-54$.

Laber, Gene and R. X. Chase, "Interprovincial Migration in Canada as a Human Capital Investment," JPE, Vol. 79 (1971), pp. 795-804.

Lee, Lung Fei, "On the Asymptotic Distributions of Some Two-Stage Consistent Estimators: Unionism and Wage Rates Revisited," mimeo, University of Minnesota (1977). , "Unionism and Wage Rates: A Simultaneous Equations Model with Qualitative and Limited Dependent Variables," International Economic Review, Vol. 19 (June 1978), pp. 415-33.

Marr, William and Frank Millerd, "Income Difference Through Migration Within Canada," Wilfrid Laurier Research Report 1978, forthcoming in Research in Population Economics, Vo1. 2, Greenwich, Conn. JAI Press.

McInnis, Marvin, "Provincial Migration and Differential Economic Opportunity" in L. O. Stone (ed.), Migration in Canada, Regional Aspects, 1961 Census of Canada Monograph, DBS, Ottawa (1969). 
Mincer, Jacob, Schooling, Experience and Earnings, NBER (New York, Columbia University Press), 1974. , "Family Migration Decisions," JPE, Vo1. 86 (1978), PP. 749-73.

Nakosteen, Robert $A$. and Michael Zimmer, "Migration and Income: The Question of Self-Selection," SEJ, Vol. 46, No. 3 (Jan. 1980), pp. 840-51.

Polachek, Soloman and Francis Horvath, "A Life Cycle Approach to Migration: Analysis of the Perspicacious Peregrinator" in R. G. Ehrenberg (ed.), Research in Labor Economics, Vol. 1, Greenwich, Conn. JAI Press (1977). Schwartz, Abba, "Interpreting the Effect of Distance on Migration," JPE, Vo1. 81, No. 5 (Sept./0ct. 1973), pp. 1153-69.

Sjaastad, Larry, "The Costs and Returns of Human Migration," JPE Supplement, vol. 70, No. 5 (Oct. 1962), pp. 80-93.

Vanderkamp, John, "Migration Flows, Their Determinants and the Effects of Return Migration," JPE, Vo1. 79 (1971), pp. 1012-31. Welland, Jon D., "Cognitive Abilities, Schooling and Earnings," Review of Economics and Statistics, Vo1. 60 (1978), pp. 622-627.

Willis, Robert J. and Sherwin Rosen, "Education and Self-Selection," JPE, Vo1. 87, No. 5, Part 2 (October 1979), pp. S7-S36. 